\title{
Rehabilitation of ectodermal dysplasia patient with a telescopic denture in the maxilla and mandibular implant assisted
} over-denture: a case report

\author{
Heba Alajami ${ }^{1}$ and Jamal Saker ${ }^{1}$ \\ ${ }^{1}$ Damascus University Faculty of Dentistry
}

September 30, 2021

\begin{abstract}
Hypohidrotic ectodermal dysplasia is a heritable disease, characterized by hypodontia, hypotrichosis, and anhidrosis. This clinical report demonstrates prosthetic rehabilitation of a patient complaining of impaired mastication and the odd appearance of her jaws. Maxillary telescopic-overdenture and implant-supported mandibular prostheses were fabricated to improve mastication, speech, and aesthetics of the patient.
\end{abstract}

\section{Hosted file}

final transcription.docx available at https://authorea.com/users/438718/articles/539824rehabilitation-of-ectodermal-dysplasia-patient-with-a-telescopic-denture-in-the-maxillaand-mandibular-implant-assisted-over-denture-a-case-report 